tion of a small portion of one potato as a treat two or three times a week. Her father being out of work, the family lived almost entirely upon bread, and the child had neither milk nor fresh meat. At the end of this time, the whooping-cough being severe, and the purpura having appeared, the mother transferred the child to this hospital, where she attended as an out-patient. The paroxyms of cough, which were of excessive violence, abated in the most striking manner under the use of tincture of Indian hemp, a remedy which, when given in full doses and carefully mixed with mucilage to prevent precipitation, is in my experience the most valuable of all the sedatives in the later stages of this disease. The purpura did not, however, disappear pari passu, in spite of the full diet and fresh vegetables which were directed to be given. Fresh crops of ecchymoses appeared from time to time. It is probable that the impoverished circumstances of the family did not permit them to feed the child properly. Two lemons were now ordered to be taken daily, and from that time the purpura faded away, and no fresh blotches have appeared for several weeks. The girl is, as you see, nearly well, and as the whooping-cough has gone, she has been received into this hospital in order to be transferred to the convalescent branch at Highgate, where the cure will be confirmed by wholesome country air.

The truth, then, with regard to these two affections, scurvy and purpura, appears to be this. Purpura is not to be regarded as a distinct disease, but as a symptom denoting a certain condition of blood and blood-vessels which occurs in several distinct diseases. The most common disease of which purpura is one of the phenomena is scurvy and I believe that the majority of cases of so-called purpura met with in this country are cases of slight or imperfectly developed scorbutus. And this view is confirmed by the fact that we meet with every gradation of the disease, from a few scattered ecchymoses to the extensive extravasations, indurations, ulcerations, and serous inflammations of its full development. All degrees arise, as a rule, under similar conditions of life-viz., scanty unvaried diet, such as the bread and weak tea which form the staple food of the London poor, foul dwellings, or lack of fresh vegetables. When these evil conditions, and especially the latter, are present in moderate degree, so-called purpura results; when they are present to an extreme degree, or their action greatly prolonged, the extreme form of the disease is produced, and so-called scurvy follows; and, lastly, the disease may arise, as in two of the cases I have shown to you, when no defect of diet or any hygienic condition can be traced, and in which the blood-fault must be due to some secret cause which has not yet been fathomed.

\section{CASE OF PULMONARY HÆMORRHAGE.}

\section{By W. J. BARKAS, L.R.C.P.Lond,, M.R.C.S.Eng., Newcastle-on-Tyne.}

THE following case came under my notice while acting as surgeon in the steamship Emblchope, on her return voyage to England from Calcutta. It is mainly curious from the large amount of blood the man lost during the last ten days of his life. He had from one to three attacks of hæmorrhage every day, the quantity varying from one and a half gills to rather more than a quart. During his recovery from the slight pneumonic attack, the pulse gradually became slower, though the temperature remained very high. The ship was for some time in very rough seas, and in a disabled,state from the engines breaking down and the hold filling with water. The waves kept washing over her decks, thus causing the sailors to be constantly at work at the pumps, while their clothes were saturated with water; and, with their usual recklessness, they would actually lie down to sleep in that condition.

The patient was J. G., aged 38 , a seaman, married, and having two children. He had undergone great hardships from shipwreck and other casualties, and had led a very laborious life-so much so that he had the appearance of a man of 50 years, though he had been all his life a careful and temperate person, and had never suffered from any severe illness. On the voyage from England he had a slight attack of bronchitis, which left an occasional short hacking cough, without any expectoration, and without any difficulty of breathing. From that time till this illness came on he felt perfectly well, with the above exception. During the afternoon of June 2 Ist, I872, he was seized with a violent fit of coughing, followed by a copious flow of red fluid blood, which coagulated into a firm clot immediately on exposure to the air. The bleeding soon ceased. On seeing him again two hours afterwards, he was expectorating blood mixed with a little mucus; the cough was very slight, with no difficulty of breathing; pulse 82 ; tongue clean ; skin moist and warm ; bowels open. There was slight dulness on percussion, and some small crepitation at the posterior portion of the base of the right lung. The heart's action was feeble, but normal. On the 22nd ( 7 A.M. $)$, he had passed a quiet night; he expectorated some pure blood, but the sputa were commencing to assume the rusty colour of pneumonia. His cough was very slight; pulse 100 ; temperature Iol deg.; no pain. He was treated by ammonia, plenty of nourishment and port wine, and by the constant application of hot poultices over the chest. At 4 P.M., there was no increase of dulness; temperature 103 deg. Shortly after this visit, he had a severe fainting fit, but soon recovered, with only a slight headache, which was relieved by cold applications. On the 23 rd, dulness on percussion was still present; he had very little cough or expectoration; pulse IOO; temperature $102 \mathrm{deg}$. On the $24^{\text {th }}$, the sputa were bloody ; pulse 90 ; temperature 103 deg. He was ordered ten grains of quinine night and morning. On the 27 th, the temperature had fallen to Ioo deg.: the quinine was continued, and he was ordered to have quinine mixture three times a day. On the 28 th, the lungs were free from dulness ; he had no cough or expectoration ; pulse 80 ; temperature 98 deg. From this date he rapidly improved, and was gradually able to resume work; but on July 7 th, alarming pulmonary hæmorrhage occurred without any previous warning. He appeared in his usual health even after the attack was over. There were no signs of phthisis, aneurism, congestion of lungs, or heart-disease. Mr. Lee, Resident Civil Surgeon, Trincomalee, saw the case with me, and was also unable to detect any cause for the hæmorrhage. I ordered him a mixture containing dilute sulphuric acid and sulphate of magnesia. On July 8th, he had had a return of the hæmorrhage, but expectorated bloody mucus. He was ordered to take 30 minims of tincture of sesquichloride of iron every four hours. On the IIth, he had had three or four attacks of bleeding. since the 8th. The quantity of blood lost in each bleeding varied from. a pint to a quart. He was ordered to take the tincture every two hours. There was no hæmorrhage until the 17 th, when it broke out to a more alarming extent than before. I now gave gallic acid in twentygrain doses, but without effect. On the Igth, I ordered him to take fifteen minims of oil of turpentine every ten minutes during the attacks, and every hour between them. This seemed to lessen the quantity of blood lost, but did not prevent the bleedings from returning. The debility rapidly increased, and the breathing was very difficult during the attacks, but not at other times, he only then feeling languid and weak. This continued till the 27 th, when he died from asphyxia, not being able to cough up the blood, which was flowing in large quantity. I was not able to obtain a post mortem examination.

\section{PARACENTESIS THORACIS.*}

By W. A. I'ANSON, Esq., M.R.C.S., L.R.C.P.Ed., Honorary Surgeon to the Prudhoe Memorial Convalescent Home, Whitley.

JAMES O, aged Io, complained of chilliness and lassitude on February Ist. During the night fever set in, accompanied with delirium and a lancinating pain in the right side. On the following day, and up to March Ist, when first seen, he had been playing about the house, although he was during each night feverish, and slightly delirious, and occasionally referred to pain in the right side.

On examination, the skin was found to be hot and dry ; the respira. tion somewhat increased in frequency, with short troublesome cough; there was also pain in the right side, inability to lie on the left side, etc. On listening to the right chest, no sound of any kind was heard except that produced by the air passing into the larger bronchial tubes; the respiration on the left side was puerile. $\mathrm{He}$ was ordered diaphoretic medicines, etc.

March 2.-During the evening the skin became moist; and through the night free perspiration set in.

March 3. 9 A.M. - The boy suffered from urgent dyspncea, and had to get the head raised. Bronchial respiration was quite gone; the right side was stationary during respiration; there was a complete dulness on percussion at the back as high as the spine of the scapula; also total absence of vocal fremitus and vocal resonance. His face was pinched and dusky-looking; pulse I 30 . Throughout the afternoon the dyspnœea was of a suffocative character, with a sense of great pressure in the neck near the right sterno-clavicular articulation. The signs of suffocation were so well marked that the parents watched over him, expecting every minute to be his last. He was again seen at 5.30 P.M., and the operation of tapping the chest was advised, as the only means likely to save his life. At my request, Dr. Philipson kindly met me in consultation, and fully coincided with the diagnosis, and necessity for immediate operative measures. The trocar and cannula (a long vulcanised Indiarubber tube being attached to the cannula, with the free end in a basin

Read before the Northern Branch. 
of warm water) were introduced into the sixth interspace, in the axillary line, and, immediately after the first ounce or two had passed, the respirations became less hurried. One pint and a half of clear strawcoloured serous fluid were withdrawn. There was complete re-expansion of the compressed lung, and, on listening, the respiratory murmurs were distinctly heard. Shortly after the operation, the little patient lay comfortable on the sound side, slept, and passed a good night.

March 4. - He expressed himself as quite well ; pulse r 20. Vesicular breathing was well heard. There were no signs of any re-accumulation of fluid.

March 6.-The respirations were quiet; there was no difficulty or pain during respiration, or when turning from side to side; pulse 100 . In the evening he had two slight rigors, shortly followed by several watery stools.

March I I. - He continued to improve; pulse 90 . He had no pain or uneasiness, and felt stronger. His appetite was good.

March I 8. - During the last four days he had been going about the house without any difficulty or accelerated breathing.

March 22. - There was no shrinking of the walls of the chest, or evidence of the reaccumulation of fluid ; the respirations were normal.

This case has been recorded as an example of the beneficial effects of the early performance of paracentesis thoracis in cases of acute pleurisy with effusion. From the time of the operation there has not been one unfavourable symptom, showing the avoidance of the formation of adhesive bands, with the gradual contraction of the affected side, and diminished power of expansion, occasionally accompanied with a partly carnified lung. Up to the present time (September), he is in excellent health.

\section{HEADACHES IN CHILDREN.*}

\section{BY W. H. DAY, M.D.,}

Physician to the Samaritan Free Hospital for Women and Children.

IN considering the subject of headaches in children, I may reasonably be accused of selecting a symptom which in some cases is the leading feature of intercranial change, and at others merely an indication of passing functional disturbance.

Diseases of the brain, whether organic or functional, are most deceptive, and difficult of detection and diagnosis. They are prone to run their course rapidly, and to terminate in death when we least expect it. They affect the mind, and may be said to influence every mental operation, concerning which our views are still speculative and open to controversy. In health and in disease general facts are required to take rank with some of the established laws of Nature, or we shall be in danger of giving to the world endless hypotheses and theories. Sound opinions, based on deductions from the conduct of Nature in disease, are the only principles on which we can depend.

Headaches at all ages and in both sexes are so common that, in the absence of cerebral disease, they barely attract our notice, and the sufferer thinks it useless to consult us. Looking at the grave termination of cases in which headache has been the chief symptom, I have thought the subject deserving especial notice. In the young and in the old they are significant, and possess a meaning which should put us on our guard, and prepare us to be ready for mischief, of which this symptom is sometimes the prelude.

In addition to the commonest varieties of headache that attack children, there is a peculiar functional form, of which numerous examples had come under my notice. I think no more suitable term than functional could be found to convey a meaning for those intricate changes of structure to which the nervous system is especially prone. I say change, because it appears to me that some change-physical, structural, or chemical-does take place in most, if not all, nervous affections, however passing and slight they may be ; and it would be conceded that it is so in childhood, when the circulation is active and the brain is undergoing rapid development. I am disposed to think that, with excess or diminution of action in a part, which we call functional disturbance, there may be associated some essential change not capable of detection. Simple congestion, constantly met with in disturbance of function, is sometimes the forerunner of exudation and morbid deposit, or of alteration of texture. Some diseases of the liver impede the circulation through the veins, and lead to effusion of serum and dropsy ; long-continued congestion of the kidney, caused by habitual exposure to cold and damp, may induce nephritis, and end in granular degeneration.

Abstract of a paper read before the Harveian Society of London.
We may proceed to inquire "What is headache? What is the degree and character of change that will produce it?" We are not sure of the exact pathological conditions of headache; we cannot say that in this case or in that case the brain is congested or anæmic, because these changes sometimes exist without it. Tumours and abscess of sume portions of the cerebral mass have been discovered, on post mortem examination, when no headache has been complained of during life. In such cases the morbid change has occurred slowly, and the brain has thus become tolerant of the pressure. Time permits the circulation to accommodate itself to the deposit, which it would not do in any sudden lesion, as a small extravasation, for instance. We may, however, generally affirm with safety that organic disease of the brain at least is attended with headache, vertigo, giddiness, convulsions, or some disturbance of function in the cerebral hemispheres; if not invariabiy amounting to headache, then to some confusion or abnormal sensation, which shows that the brain is involved. We shall generally find that uneasy sensations, if not actual pain, are the accompaniments of alteration of structure within the brain, whether there be morbid growth, chronic softening, or the changes due to inflammation.

Headaches calling for separate discussion are found under the titlesI. Cerebral headache, attributable to injury. 2. Gastric or sick headache. 3. Headache from anæmia and neuralgia. 4. Headache depending on plethora or fulness of blood. 5. Headache depending on some intricate change in the cerebral membranes or tissues of the brain-a condition amenable to treatment at an early stage. 6. Epileptic headache. We may incidentally mention the severe headache of fever, especially in the young and robust sufferers from typhus. Headache is severe and continuous in relapsing fever, and sometimes in typhoid fever.

Of the form of headache depending on some peculiar cerebral change, it may be observed that there is occasionally, but by no means often, some enlargement of the head ; and, if this state continue without improvement, it is apt to grow disproportionately to the rest of the body, and the extremities waste, the muscles become flabby, and the joints loose. The enlargement of the head is mainly noticeable at the upper part of the forehead and occiput, and sometimes at the sides of the head immediately above the ears. The increase of size is symmetrical. The leading symptoms are pallor and debility, restlessness at night, irritability by day : sometimes these little patients are sullen and indifferent to what is going on ; at others, very fidgety and quarrelsome on the slightest provocation; there is sighing and yawning, and exhaustion is marked in every act. What are the changes that take place within the cranium? Is the brain simply exhausted? Is its texture softer than normal ? and has excess of fluid replaced any portion of the solid mass? Headache is the symptom which, beyond all others, prompts the parents to seek our aid, and which first draws their attention to the child's state. The cause of all the mischief is located in the brain or its membranes. The slow and sometimes irregular pulse, with dull and persistent headache, taken with other symptoms, makes us fear the approach of organic disease. The temperature is normal, and, if the cases be seen early, they recover.

As to treatment, most forms of headache are unsuited for tonics at the beginning. In the last class of cases, they may be said invariably to aggravate the mischief, till the system is prepared to receive them. Certainly headache of cerebral origin, which disturbs secondarily the nutritive processes, will be increased by the attempt; and, if the stomach be primarily at fault, we shall be equally disappointed with steel wine and bark. In all cases of the kind which I have last described, the latter remedy had to be carefully added, and in many instances, even in small doses, it had to be relinquished. Bromide and iodide of potassium act as specifics in the early stage; but, when once the headache is relieved, their continuance would be too depressing, and iron and codliver oil must be employed to complete the cure.

\section{CASE OF HYDROPHOBIA.}

\section{By NELSON C. DOBSON, F.R.C.S., Surgeon to the General Hospital. Bristol.}

AT this time, when the subject of hydrophobia is being discussed not only in the public press, but also in the medical journals, the following notes taken from my private note-book of a case which occurred at $\mathrm{St}$. Thomas's Hospital during the time when I was house-surgeon may be interesting, especially as I saw the man from beginning to end - that is, at the time when he was bitten, and also when the symptoms to be presently detailed occurred.

John Wells, a working engineer, aged 57, a somewhat pale but hearty-looking man, who had always been temperate, applied for 